\title{
Energy Saving Measures and Strengthening Thermal Insulation Construction Technology in Residential Building Design
}

\author{
Yongzhi Li ${ }^{*}, 1$ and Alan A. Horrobin ${ }^{2}$ \\ ${ }^{1}$ Jilin Justice Officer Academy, Changchun 130062, China \\ ${ }^{2}$ Department of Sociology, Anthropology and Criminology, University of Windsor, Windsor 999040, Canada
}

\begin{abstract}
The study was majorly focused on energy-saving measures and strengthening thermal insulation construction technology in residential building design. Through the comprehensively detailed analysis on the energy-consumption issue of residential buildings, the researcher has realized the necessity of energy saving and thermal insulation, which also initiated the reflection and the further-launched discussion on energy-saving measures and thermal insulation construction technology. In the study, the researcher explored and analyzed mainly on several aspects, the factors to consider in energy saving and thermal insulation, the specific energy-saving measures and strengthening thermal insulation construction, and gave many energy-saving measures and thermal insulation constructions that have good application prospect and practical value. Meanwhile, the researcher also simply researched on the preoccupations of these technologies, key design ideas, technical key points and technology implementation standard, as well as briefly introduced them. This study possesses a certain guiding significance for the energy-saving measures of implementation and thermal insulation construction technology selection in the residential building design. By reference to the study, it is possible to make energy-saving measures and thermal insulation construction technology choices in residential building design more extensive and practical, which has significant meaning for building energy consumption reduction.
\end{abstract}

Keywords: Energy-saving measures, residential building, thermal insulation construction.

\section{INTRODUCTION}

In the actual residential building design, the fact that the understandings in energy-saving measures and thermal insulation technology are not fully comprehensive and detailed often brings out great energy consumption in residential building, increase in the construction cost and certain waste of energy. Through the cognition on problems and the anatomy on measures and technologies, this study discussed the issues of selection and design details in energy-saving measures and thermal insulation construction technologies and the related regulations and standards, so that people can understand more comprehensively energysaving measures and thermal insulation construction technologies.

\section{THE NECESSITY OF ENERGY-SAVING AND THERMAL INSULATION CONSTRUCTION DESIGN}

\subsection{Reduce Energy Consumption}

As often said, China is a country that possesses vast territory and abundant resources, but at the same time it is people live in this land with an area of 9.6 million square also a country with a large population. More than one billion kilometers, which means in average per capita energy is not rich. What's more, progress of the society, development of economy and improvement of people's material living standards makes the problems caused by energy consumption increasingly worse. And the energy consumption in residential buildings is a rather serious aspect in the problem of energy consumption. Now have a look below the severity of these problems through some statistical data in 2012. Revealed by the comprehensive summary calculation on the respective energy consumption of residential buildings and building materials, the energy consumption produced in design and construction of residential buildings accounted for as high as $37 \%$ of the national total energy consumption.

According the statistics, $30 \%$ of land in built-up area in city was used for the construction residential buildings, which accounted for $20 \%$ of the national total energy consumption; while $32 \%$ of water resources in city is consumed in residential buildings; steel consumption accounted for $20 \%$ of the national total steel consumption, and cement consumption accounted for $17.6 \%$ the national total consumption [1]. The most serious fact that the data is also increasing year by year made it is pretty plain to see that the problem of energy consumption caused by residential building design is very serious, which also initiated people's reflection on the energy-saving measures and strengthening thermal insulation construction technologies. All in all, these data has fully demonstrated the necessity of the application of energy-saving measures and of strengthening thermal insulation construction in residential building design. 


\subsection{National Condition Reasons}

As above statistics revealing, the problem of building energy consumption in China is increasingly worse day by day and has largely impeded the economic construction and society development, which has made economizing and fully utilizing energy a focus topic. The residential buildings most closely connected to people's daily life takes the first place in energy consumption. If people make full use of resources and reduce energy consumption, the sustainable development of the city will be realizable, which also is of great significance for the construction and development of China. In addition, the relevant policies recently promulgated by Chines government have given a series of requirements on energy-saving measures and strengthening thermal insulation construction. For example, for the cold regions in northeast and northwest China, the government put forward the mandatory energy-saving standard which must reach more than $65 \%$; while for the regions with hot summer and cold winter, the mandatory energy-saving standard by government must be over $50 \%$. Moreover, the government's requirements on building energy saving are not only the mandatory energy-saving standards, but also practiced in the construction norms and the corresponding standards to set many standards and related technical regulations, such a s "Thermal Design Code for Civil Building", "Energy-Saving Design Criteria For Civil Building" etc.

These building codes and related standards have put forward new requirements on energy-saving measures and strengthening thermal insulation construction in residential buildings, and the positive corresponding national policies and comprehensive practice of energy saving design and thermal insulation construction design are also very necessary.

\section{ENERGY SAVING DESIGN}

\subsection{The Factors to Consider in Energy Saving Design}

\subsubsection{Building Performance}

The starting point of energy-saving thermal insulation construction design is to solve the problem of extravagant energy consumption in actual buildings, but it must take the building performance as the premise, that is to say, it must guarantee the living comfort level of residential buildings. Firstly, energy saving measures for these types of buildings should be in accordance with the principle of suiting one's measures to local conditions and obtaining raw material locally, introducing scientific, reasonable and advanced energy-saving measures and thermal insulation constructions to reduce building cost. Moreover, energy-saving thermal insulation construction design of residential buildings also need to consult the regional environments and climate changes of building location to adapt to and combine with these natural environment factors, on the basis of which, to choose different energy-saving measures and thermal insulation constructions based on the variety of climates and pay attention to the body of building for better energy saving in building. The building energy-saving thermal insulation design has put forward the new requirements on the radiating surface and heating surface of the building body [3]. On one hand, it requires that the shape coefficient of building should be as small as possible and correspondingly the radiating surface should also be rather small. On another hand, in the wintertime radiating surface of building should be as large as possible, which, especially in the regions with hot summer and cold winter, can save energy better by heat radiant and ventilation. For the 2 sides, the contradiction between size and radiating or heating surface is a main problem in building energy-saving insulation construction which also has serious influence on the performance of residential buildings. Only when this contradiction is well resolved by taking effective measures, can the using performance of residential buildings be guaranteed and requirements on energy-saving thermal insulation construction of residential buildings be meet [3].

\subsubsection{Combination with New Energy Application}

Since most of the building materials except a few steel bars are unrecyclable, energy saving can be produced not only by reducing energy consumption but also by new energy introduction and binding application which can also engender pretty good energy saving efficiency. In twentyfirst Century, the concept of environmental protection and energy saving has won support among the people and various energy-saving technologies have been gradually applied to practice. The most typical one is the development and utilization of solar energy. In addition, the reasonable development of geothermal pump system and wind energy utilization system methane and the exploitation of methane, natural gas and other new energy which are based on the local environment and geographical conditions of residential buildings are functioning very well. It is urgent to be stressed that the exploitation and application of these technologies should be combined with the local geographical environment. And the whole technology or system should also be optimized step by step through consistent guidance and improvement at an orderly gradual pace. Lastly, in the process of development and application, the continuing exploration and research are required for the persistence of better promotion and application.

\subsection{Saving-Energy Design Plan}

\subsubsection{Arrangement and Shape of Building}

The two basic requirements of the residential buildings are lighting and ventilation. And the geographical environment of the resident building as well as its height, forwarding direction, interval distance, the arrangement of transportation network and the surrounding green construction are all the influencing factors for lighting and ventilation. Besides, all the factors are still influencing the energy consumption in the actual service of the residential building. As a result, it is very vital to stress the arrangement and shape of residential buildings. In the design process, firstly a practical observation on the surrounding environment should be conducted to covey a comprehensive consideration of environment factors and natural climate factors. And then, a deep insight to the local customs, cultures, and residential behavior models is also required. In addition, the function of residential building is another noticing point. Based on the interval distance, forwarding 
direction, arrangement, wind direction, sunshine radiation and the outer-constructing environment, a comprehensive consideration on multiple aspects can be formed to conduct the optimization design of building's arrangement and shape and full utilization of nature factors. And the design improvement of the factors can be changed by human should be done for the purpose of energy-saving thermal insulation. For example, in the choice of building's forwarding directions, the south-to-north direction should be the priority option to improve the ventilation in summer and prolong the sunshine radiating time in winter to avoid the emergence of radiation inadequatity issues. In the conduction of design, concerning the building energy saving, the unevenness on the building body should be reduced as much as possible. The shape coefficient of heating-type residential buildings should be controlled within 0.3 ; the house depth should be reasonably expanded, suitably between $10 \mathrm{~m}$ and $14 \mathrm{~m}$; and the house length should be controlled around $55 \mathrm{~m}$. Moreover, in the overall planning, the building design in the regions with hot summer and cold winter should reasonably adopted the plan of monomer combination for the formation of air duct to fully utilize the nature wind and thus reduce the energy consumption of air condition. The implementation of building structure energy saving is shown in Fig. (1) as follow.

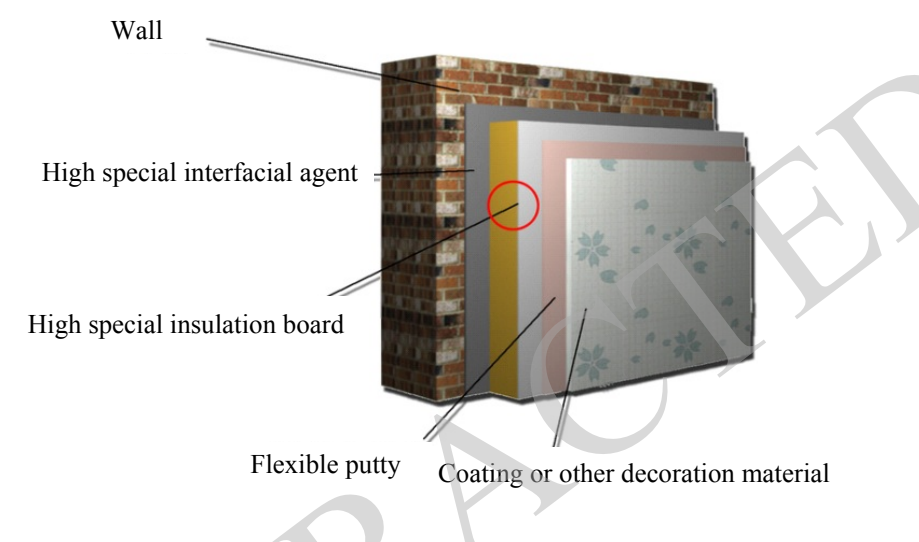

Fig. (1). Figure of building structure energy-saving implementation.

\subsubsection{The Graphic Design}

The aim for the graphic design is to meet the requirements of households which cover family composition, value and life style etc. Mainly, the requirements can be categorized into several aspects, lighting and ventilation, multiple functions, comfortable degree, functional layout and area using rate. Meeting the demands above, energy-saving residence should also be designed with the consideration of the building's aspect, the temperature damping area and the distribution of thermal environment. The aspect of residence should be structured, and the peripheral area should be reduced, in order to increase the radiating area in winter and decrease the direct sunlight in summer. For example, putting one side with larger area of external wall and more windows toward the south where the solar radiation is intense, in order to gather solar energy effectively. Setting up some smaller windows in northern external wall so that the demand of ventilation can be satisfied. In addition, we can set up smaller windows selectively or even not in an east-west direction, preventing the intense direct sunlight. When considering kitchen, passage and toilet which are not sensible with thermal environment, we can place them in the north, in the contrast we should intercalate bedroom in the south as far as possible, to enhance the utilization efficiency of solar energy. In modern architecture, we can also make some temperature damping area to reduce the dissipation of heat conduction. For example, in the area of cold in winter and hot in summer, we can replace open-plan stairs by enclosed-plan ones, and install windows in staircase. Entrance of buildings facing north can be fitted with anteroom against the invasion of northwest wind in winter. Furthermore, we can control the air current indoors with the help of rational settings, on the purpose of creating a splendid environment indoors.

\subsection{The Building Envelope and Material Design}

The main structure of the building envelope, including a portion of the enclosed space and the outdoor portion of the spacer, the material points that the materials and surface decoration materials which are used by these portion of structures. In the residential building envelope, the energy consumption is the largest part of the roof, doors, windows, walls and floor and so on. Among them, the roof accounted for $22 \%$ in the overall energy consumption in buildings, the proportion of windows and doors accounted for $33 \%$, accounting for $24 \%$ of wall, floor accounted for $15 \%$. The amount of heat of maintaining structure is very large, as shown in Fig. (2). Residential building envelope is mainly design for meeting the interior lighting and ventilation requirements, meanwhile, providing the proper heat, moisture protection for the interior space [6]. We can obviously see from the ratio of envelope occupied and the role of its importance, in order to achieve the purpose of energy-saving in the structure of building energy consumption, you can start from the roof, doors, windows, walls and floor construction and other aspects of the body. In the overall structure of the building envelope, roofing possession ratio is usually small, then the role is very important. Therefore, when you are processing to optimize the design of the roof, you can choose a small density of application and correspondingly smaller thermal conductivity of insulation materials, thereby reducing the weight and thickness of the roof. However, the roofing material cannot select a larger absorption insulation material. Because in the wet operations of the roof, if the roofing material having a larger water absorption, it will generate the effect of water absorption, thereby reducing the thermal insulation effect [6].

\subsubsection{Roof Energy Saving}

Though the roof covering area occupies a small proportion on exterior-protected construction, the roof covering have an important effect on top floor housing construction. The measures of roof energy saving can mainly through the following aspects. First, the choosing of the roof insulation material. To avoid the roof have a too heavy weight and thickness, the high density or the high thermal conductivity material are not be concerned. Second, roof insulation materials could not be water absorption materials, 


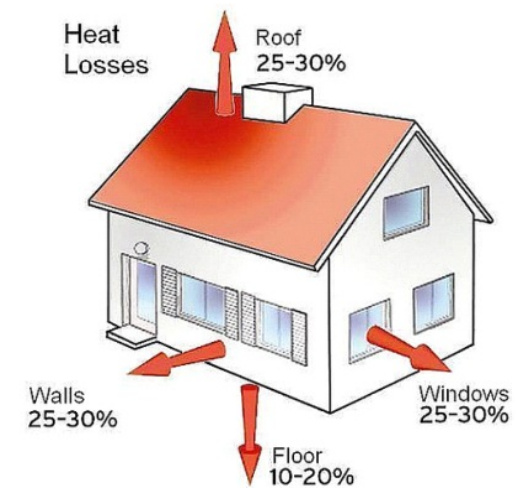

Fig. (2). The diagram of the Maintenance of structural heat radiation.

to avoid the impact of the insulation effect thanks to the wet work. As far as the information on the current market, roof insulation energy saving material are more like Overhead type heat insulation cotton, Inverted insulating roof and Pumice sand roof and other energy-saving insulation roofing. As for the southern residential buildings, must pay more attention on the effect of insulation, energy-saving design could through the planted roof, sun roof or high relativity roof.

\subsubsection{Energy Saving of Walls}

Energy saving technology of walls is the use of composite wall design to save energy. Composite energysaving wall refers to increase in a composite insulation material layer or several layers at the basic body structure, to improve thermal performance to achieve energy-saving insulation. Composite wall technology are more taken advantages of new efficient thermal insulation material, such as rock wool, glass wool, polystyrene, polyurethane foam and so on. And even direct use composite wall, to control the heat conduction coefficient of the wall, so as to achieve the purpose of energy-saving insulation. According to the position relationship between the composite and the main structure, it can be divided into external insulation technology and internal insulation technology. The inner insulation of the outside box is the internal insulation layer construction carrying out in the outside wall. It is a thermal insulation energy-saving technology which is applying widely. Exterior insulation technology is more reasonable than insulation with its obvious advantages and has a better thermal insulation effect by the application of the same specification equal performance and size of the heat preservation material construction of external thermal insulation structure, not only reduces the thermal bridge effect of building structure, but also improves the effective space of buildings inside the body. At the same time, it also can effectively eliminate the condensation phenomenon, improve the residential living comfort. In the south in hot summer and cold winter area, exterior decorative color choice should try to choose light color, in order to reduce solar radiation absorption coefficient. The heat insulation effect of building energy diagram as shown in Fig. (3), left for the insulation effect before use, the right for the insulation effect after use.

\subsubsection{Energy Saving of Outdoors and Windows}

According to the relevant statistics, the loss of heat energy consumption through external doors and windows accounted for about $35 \%$ to $45 \%$ of building energy consumption. Which can be seen, external doors and windows energy saving technology application is still weak in the enclosure structure energy saving technology application. The selecting of the external doors and windows materials and glass materials, and the shading measures will affect the thermal performance of exterior doors and windows. The more common Ordinary single glass aluminum alloy window can reach $6.4 \mathrm{~W} / \mathrm{m}^{2} \mathrm{~K}$, is six times of the wall heat transfer coefficient. So, the application of new energy-saving insulation materials is more important. Such as hollow glass, reflective glass, heat absorbing glass. The double glass hollow double cavity is in good thermal performance, whose thickness is only $40 \mathrm{~mm}$. Window selection is the alloy insulation section bar. The heat transfer coefficient can reach $1.5 \mathrm{~W} / \mathrm{m}^{2} \mathrm{~K}$ [7].

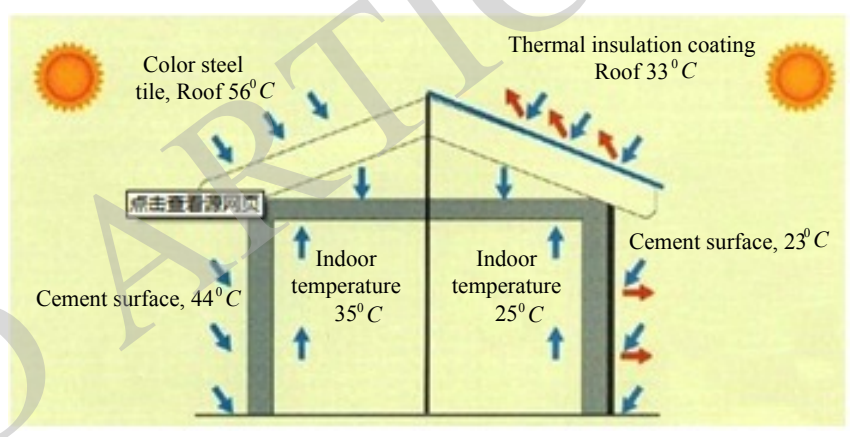

Fig. (3). Effect of heat insulation for building energy-saving diagram.

In addition to the selection of the external doors and windows, the area of the external doors and windows is also an important factor to affect its energy saving effect. The determination of the external area needs to be combined with the local climate factors, winter and summer sunshine, outdoor temperature changes, wind conditions, indoor lighting and ventilation design and other factors outside the door and window area. Generally speaking, in the premise of ensuring the lighting and ventilation, it should be reasonable to control the ratio of windows and walls of all orientations, as is shown in the following table. The North should not be greater than $25 \%$, the South should not be greater than $35 \%$, the north and south should not be greater than $30 \%$. The controlling of all towards the area ratio is shown as Table $\mathbf{1}$.

\section{THERMAL INSULATION CONSTRUCTION TECHNOLOGY}

In residential building design, insulation construction technology is mainly used in the roof design of building envelope. This paper is mainly took the winter warm summer heat area residential building design as an example, through the strengthening analysis of the technical measures applied to thermal insulation construction, to explore the effect of energy saving thermal insulation construction technology plays in the residential building. Following the 
roof vaporated thermal insulation construction, roof insulation and reflected sun planted roof structure aspects, carries on the analysis of residential building energy saving effect of thermal insulation construction technology.

Table 1. The controlling of all towards the area ratio.

\begin{tabular}{|c|c|c|c|c|}
\hline Orientation & East & West & South & North \\
\hline \hline area ratio & $=<30 \%$ & $=<30 \%$ & $=<35 \%$ & $=<25 \%$ \\
\hline
\end{tabular}

\subsection{Roof Heat Insulation Structure}

There are mainly four Roof heat insulation and cooling structure methods in the architectural design in warm winter and hot summer areas. The first is the ventilation heat insulation roof layer. The second is the roof vegetation heat insulation. The third is the roof vaporated thermal insulation. The forth is the roof reflecting sunlight heat insulation. The passive evaporation insulation roofing can transform and control effectively without relying on the heat from Conventional energy on the roof of solar radiation, integrated temperature outside, and the Indoor thermal environment. This is because that the peculiarity of Water evaporates away a lot of heat absorption of latent heat of vaporization are fully utilized in Passive evaporative heat insulation structure. To obtain good energy-saving and heat insulation effect, so as to achieve the requirements of the design of residential building energy saving. Reflective insulation is mainly applied coating reflection insulation. Paint reflectance spectra is shown as in Fig. (4) below.

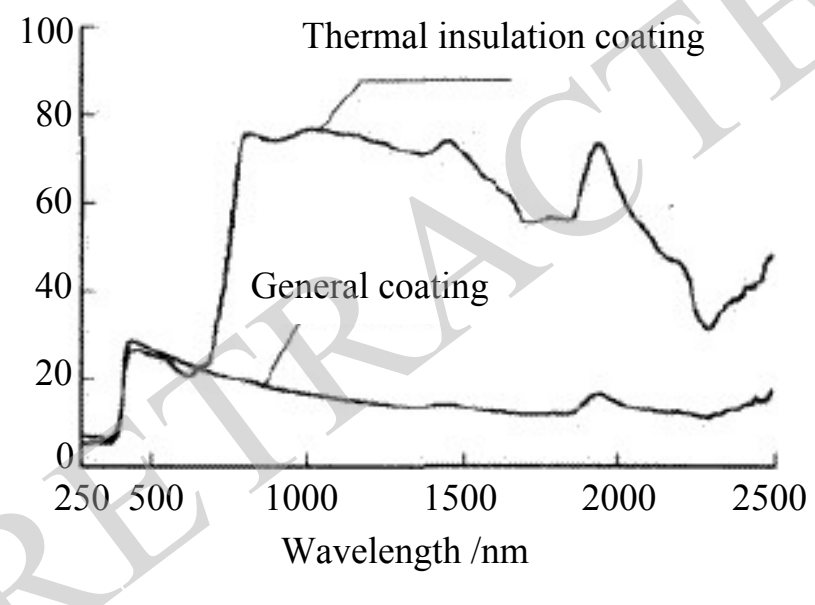

Fig. (4). Coating reflection spectra.

\subsection{Planting Roof Heat Insulation Structure}

In Chinese areas with hot summer and warm winter, planting roof heat insulation structure is a kind of common heat insulation roof. Which utilizes cultivated plants to form a wet soil system, through absorption, evaporation and transpiration, and improve the balance system of roof implementation, to reduce the impact of direct sunlight and other factors outside of the indoor environment. And this roof planting technology can effectively reduce the Strong direct effects on heat, cold air on roof form. And To reduce the surface temperature fluctuations, forming a good protection to the indoor environment temperature. The basic structure level is as shown in Fig. (5).

\subsection{The Roof Sunshine Reflection Insulation Structure}

There are many kinds of design scheme of roof sunlight reflection heat insulation structure. One of the more significant heat insulation effect is inverted roof insulation construction way of reflecting sunlight. The waterproof layer is placed above the heat insulation layer, to effectively protect the waterproof layer, making the indoor environment from the external environment.

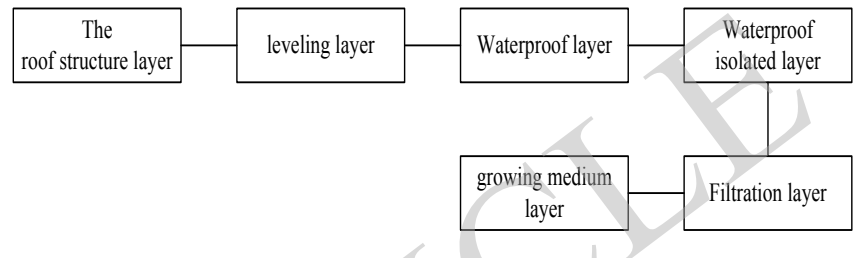

Fig. (5). Planting roof heat insulation structure diagram.

\section{CONCLUSION}

Only on the basis of understanding the energy-saving measures and thermal insulation construction technology, can the measures of energy saving and thermal insulation construction technology be chosen rightly, can the design of energy-saving programs and heat insulation scheme be right, and to achieve energy-saving and insulation purposes better. The development of society and science will lead to the development of technology, which will also more research to explore more reasonable energy-saving measures and thermal insulation construction technology.

\section{CONFLICT OF INTEREST}

The author confirms that this article content has no conflict of interest.

\section{ACKNOWLEDGEMENTS}

Declared none.

\section{REFERENCES}

[1] J. Lin, "On area design of residential building energy saving hot summer and cold winter area", Embodies Scientific Research Sichuan Building, vol. 36, no. 4, pp. 264-267, 2010.

[2] Y. B. Xue and Martin, "Residential building south to open the balcony energy saving design of architecture technology", Architecture Technology, vol. 44, no. 1, pp. 79-81, 2013.

[3] X. M. Liu, "The design and application of architecture technology of silicon panels in energy-saving residential building", Architecture Ttechnology, vol. 41, no. 3, pp. 264-266, 2010.

[4] R. Z. Wang, Y. M. Qian, and T. H. Wang, "A comprehensive analysis of architecture technology influence the shape of multistorey residential building energy saving effect", Architecture Technology, vol. 41, no.3, pp. 276-279, 2010.

[5] C. D. Golghate and M. S. Pawar, "Development of Green Supply Chain for Plastic Films Manufacturing Industries in India: Ranking of Challenges using Analytic Hierarchy Process", Advances in Industrial Engineering and Management, vol. 3, no. 4, pp. 45-58, 2014.

[6] K. H. Yu and Z. H. Zhang, "Building energy saving and emission reduction of the international experience and Enlightenment", Construction Technology, vol. 43, no. 3, pp. 266-269, 2012. 
[7] H. R. Dong and S. M. Qi, "Building surface material absorbs solar radiation effects on the properties of heat consumption of building", Building Technique, vol. 43, no. 8, pp. 752-754, 2012.

[8] J. Xiao, P. Zhao, and F. Jing, "Building energy conservation technology research on efficiency evaluation", Construction Technology, vol. 43, no. 12, pp. 1078-1079, 2012.
[9] H. Zhu, R. Xin, J. P. Liu, and W. Y. Pan, "The common problems and Countermeasures of construction technology for energy saving design of high rise office building", Construction Technology, vol. 27, no. 4, pp. 13-18, 2011.

(C) Li et al.; Licensee Bentham Open.

This is an open access article licensed under the terms of the (https://creativecommons.org/licenses/by/4.0/legalcode), which permits unrestricted, noncommercial use, distribution and reproduction in any medium, provided the work is properly cited. 